\title{
Incorporating Ethics into Strategic Management with Regards to Generation Y's View of Ethics
}

\section{Celikdemir DZ* and Paker IT}

Department of International Logistics Management, Faculty of Economics and Administrative Sciences, Yasar University, Turkey

\begin{abstract}
Generation $Y$, also called the Net Generation or Millennial refers a collaborator of the population larger than the Baby Boom generation. With approximately 80 million people born from mid-1980 to 2000, this group is the most recent generation to enter the workforce. Workplaces are being redefined and organizations are being pressed to adapt as this new wave of workers inspire into business environments. It is widely accepted that distinct generational experiences shape ethical ideologies and ethical ideologies in turn affect the way people function in the workplace. Age-based differences in perspective and complaints about other generations are certainly not a new phenomenon. Businesses committed to high ethics standards know how important it is to create a shared sense of values and a cohesive culture rooted in integrity, where organizational values and personal values align. Shaped by significant events, societal trends, and the cultures of their organizations, each generation develops its own unique perspective of what constitutes right and wrong behavior on the job. Correspondingly, Gen Y's unique collaboration experiences are likely to shape their ethical ideologies and consequent workplace judgments and actions. In this study, we examine Gen Y's ethical ideology and its reflections on strategic management essentials. This group of people is an important part of the workforce since they are the near future managers of the business life. The purpose of the research is to better understand the impacts of Generation Y's ethical ideology and how this ideology reflects to their practice in business. In order to analyze their ethics view, qualitative approach is held. Interviews with individuals whom are to be considered as employees from Gen $Y$ are conducted to identify ethical attitudes and behaviors. Especially, the changing ethics view on corporate business life and the effects on strategic management are focused in this research. The research will try to explore how ethical ideology has changed conditionally with the changing generation behaviors. The interviews are held with 8 employees. The interviews are transcribed into data which are analyzed by the researches to identify the findings. Qualitative approach is advantageous since it helps to gain detailed feedback about feelings, attitudes and behavior. The research will contribute to the literature by considering the impact of varying ethics view for Generation $Y$ and how it reflects to the business life environment in today's global world.
\end{abstract}

Keywords: Ethics; Generation Y; Strategic management

\section{Introduction}

Generation Y, with approximately 80 million people born from mid-1980's to 2000, is the most recent generation to enter the workforce. Much has already been written about the changing work styles, wants and needs of this generation, and the need for radical responsive changes in the workforce, including the way managers lead this new generation of workers [1]. There is a clear need for research that focuses specifically on Generation Y (Gen Y). Such understanding is essential for managing current workplace ethical conduct and for understanding the impacts on ethical climates of organizations in the near future. In this article, we examine how Gen Y ethical ideologies relate to ways they work with others, lead others, and judge ethically questionable behaviors. With respect to leading others, we focus on the servant leadership construct because of its special emphasis on personal integrity and ethical conduct $[2,3]$.

To understand the ethical ideologies of Gen Y, we first must consider their distinct cohort experiences. Academic literature has argued that ethical judgments, decisions, and behaviors tie back to the unique experiences that shape generational cohorts [4]. Generational theory points to common experiences in political, social, and historic contexts as being major influencers of ethical values, especially during the time when an individual is coming of age. Ramsey et al. note that the literature "provides evidence of persistence in ideologies created by unique historical events," and that "a cohort process rather than an aging process tends to explain the differences in ethical judgments".

Businesses committed to high ethics standards know how important it is to create a shared sense of values and a cohesive culture rooted in integrity, where organizational values and personal values align. Strong ethics cultures rely, in part, on a clear, shared understanding of "right" and "wrong," so employees understand their responsibilities and clearly know what it means to "do the right thing." Age-based differences in perspective and complaints about other generations are certainly not a new phenomenon. Every generation has a moment (or several) when they throw up their hands and ask, "What's wrong with them? Why don't they just get it? Why are they so slow to learn?" The differences become even more important when it comes to workplace conduct, e.g., everything from appropriate use of the company credit card to gathering information on competitors to sexual harassment.

Generational differences in perspective and in work style can make the difficult task of culture-building even more challenging. When

${ }^{*}$ Corresponding author: Deniz Zaptcioglu Celikdemir, Department of Chair and Professor of International Logistics Management, Faculty of Economics and Administrative Sciences, Yasar University, University Street, No. 37-39, Wooded Road, Bornova, Izmir 35100, Turkey, Tel: +902324115000; E-mail: deniz.celikdemir@yasar.edu.tr

Received January 06, 2016; Accepted February 10, 2016; Published February 20, 2016

Citation: Celikdemir DZ, Paker IT (2016) Incorporating Ethics into Strategic Management with Regards to Generation Y's View of Ethics. J Bus Fin Aff 5: 175 doi:10.4172/2167-0234.1000175

Copyright: ( $) 2016$ Celikdemir DZ, et al. This is an open-access article distributed under the terms of the Creative Commons Attribution License, which permits unrestricted use, distribution, and reproduction in any medium, provided the original author and source are credited. 
communication goes awry and cues are misread, it is easy for shared values to manifest themselves in different and even contradictory ways. Shaped by significant events, societal trends, and the cultures of their organizations, each generation develops its own unique perspective of what constitutes right and wrong behavior on the job. Businesses are not powerless against the forces of generational change and the challenges faced by less-experienced workers. Companies committed to integrity can and do make concerted efforts to meet the ethics challenges they face - by putting in place robust ethics and compliance programs and building strong ethics cultures. But as it turns out, ethics and compliance programs and ethics cultures influence the generations differently.

While this generation does appear to hold some core ethical values, they also hold a relational view of ethics which influences how these values play out. We posit that this interesting mix of experiences and characteristics of Gen Y'ers affects (a) their ethical ideology [4], which in turn influences, (b) their workplace leadership style, (c) their approaches to workplace team situations, and (d) their responses to individual and collaborative workplace ethical violations.

\section{Literature Review}

\section{The features of gen $\mathrm{Y}$}

Generation Y are a group of people born during the '80s and the early ' 90 s. The name is based on Generation X, which is the peer group that came before them. Generation Y people may be known as echo boomers because they are the children of baby boomers, or someone who was born during the period of increased birth rates that occurred between 1946 and 1964. The Generation Y cohort is also referred to as Millennials, the Internet generation and/or the Net generation. Generation Y legal professionals are in their 20s and are just entering the workforce. With numbers estimated as high as 80 million, Generation $\mathrm{Y}$ is the fastest growing segment of today's workforce.

Here are the some main characteristics of this group of people:

- $\quad$ One of the most specific features of Generation Y is that they grew up with technology and rely on it to perform their jobs better. Armed with iPhones, laptops, cellphones and other gadgets, Generation $\mathrm{Y}$ is plugged-in 24 hours a day, 7 days a week. This generation prefers to communicate through e-mail and text messaging rather than face-toface contact and prefers webinars and online technology to traditional lecture-based presentations. Learning for them is more than just traditional brick and mortar college campuses. They also have access to presentations via webinars and online classes.

The fast-track has lost much of its appeal for Generation Y who is willing to trade high pay for fewer billable hours, flexible schedules and a better work/life balance. While older generations may view this attitude as narcissistic or lacking commitment, discipline and drive, Generation Y legal professionals have a different vision of workplace expectations and prioritize family over work.

Nurtured and pampered by parents who did not want to make the mistakes of the previous generation, Generation $\mathrm{Y}$ is confident, ambitious and achievement-oriented. They have high expectations of their employers, seek out new challenges and are not afraid to question authority. Generation Y wants meaningful work and a solid learning curve.

As children, Generation Y participated in team sports, play groups and other group activities. They value teamwork and seek the input and affirmation of others. Part of a no-person-left-behind generation,
Generation Y is loyal, committed and wants to be included and involved.

Generation $\mathrm{Y}$ craves attention in the forms of feedback and guidance. They appreciate being kept in the loop and seek frequent praise and reassurance. Generation $Y$ may benefit greatly from mentors who can help guide and develop their young careers.

As adults, Gen Y's are confident in themselves and their future, motivated, goal oriented, optimistic, assertive, and they believe they are "right". As a result, they feel pressured to succeed and think others should be flexible with them when they want to negotiate scheduling conflicts. They prefer to work in groups, and are group oriented rather than being individualistic [5]. An egalitarian leadership style (democratic approach) is best suited to this generation because they do not particularly conform well to hierarchies. Gen Y also has been classified as exceedingly narcissistic. In fact studies done by Twenge and Foster have shown that the average college student in 2006 was 30 $\%$ more narcissistic than the average student in 1982 [6]. This implies a focus on self at others' expense, or at least a failure to consider the impact of one's workplace behaviors on others-a critical component of higher-level ethical perspectives and of effective interpersonal work behaviors (e.g., teamwork).

Taking into account the personal characteristics of this generation, it can be said that they show very distinct differences when it comes to business life. Gen Y's appear to observe fewer boundaries than previous generations and are more flexible about when and how to apply them. In being more open and transparent, they become more likely to discuss work activity with a wider range of people both in public and in private. Their flexibility might make Gen Y's more likely to engage in or tolerate behavior that many consider unacceptable. Additionally, they are the most at-risk group of the four generations, as they are more likely to observe misconduct and experience retaliation after reporting it. However, there is some encouraging news about the youngest generation. Gen Y's entering the workforce have shined the light more readily on misconduct than the youngest entrants in previous years. In fact, Gen Y's were more likely than their older cohorts to utilize the resources of ethics and compliance offices. Finally, Gen Y's are more likely to respond to the elements of ethics and compliance programs that include social interaction and provision of support (e.g., helplines, mechanisms for seeking advice, training) (2013 Ethics Resource Center)

This age group is moving into the labor force during a time of major demographic change and sixty-year-olds are working beside 20 -yearolds. Freshly minted college graduates are overseeing employees old enough to be their parents. And new job entrants are changing careers faster than college students change their majors, creating frustration for employers struggling to retain and recruit talented high-performers. Unlike the generations that have gone before them, Gen Y has been pampered, nurtured and programmed with a slew of activities since they were toddlers, meaning they are both high-performance and highmaintenance. They also believe in their own worth. "Generation Y is much less likely to respond to the traditional command-and-control type of management still popular in much of today's workforce," says Jordan Kaplan, an associate managerial science professor at Long Island University-Brooklyn in New York. "They've grown up questioning their parents, and now they're questioning their employers. They don't know how to shut up, which is great, but that's aggravating to the 50-year-old manager who says, 'Do it and do it now.' 


\section{Strategic management}

Strategy as a word traces back to Greek. As a term it is related with words "army" and "lead". In Greek, it means "a general" and its definition is "to destroy enemies through effective use of resources" [7]. However, its use in business appeared after World War II within the changes taking place throughout the world which was leading to a competitive environment. The changes in firms and in technology ended up with an increment in the competition which caused an unstable environment [8]. Many scholars have studied strategy as a concept in field of business [9-12]. According to the studies of scholars, business strategy should be used as a tool which would enable organization to realize its main goals through effective use of resources in accordance with the outcomes of organization's environmental and situational analysis. Therefore, strategic management is defined as the implementation of business strategy which has been developed [7].

Strategic management analyzes the internal and external environment of an organization to enhance the use of resources to attain its organizational goals. It also helps organization to deal with change [7]. Throughout the strategic management literature, it is mentioned that organization is an open system which survives within an independently given environment [13]. It is crucial for managers to sustain accordance between organizational needs and environmental constraints [14]. Thus, it can be stated that strategic management forms a framework for organization. While forming the framework, the most familiar method is SWOT analyses which points out the strengths and weaknesses of an organization through internal analysis and also determines the opportunities and threats waiting by external analysis [15]. This would help managers to figure out their business strategies and long term plans. Also, it would enable them to adapt to changes taking place in their environment which may help to gain competitive advantage. Through the environmental scanning, managers are able to formulate and implement strategies. For the last step, they should evaluate and control whether these strategies enable them to attain their goals which are set in their plans [16].

After environmental scanning is completed by using SWOT analysis, the organization should formulate their strategies. In this phase, the organization should define its mission and vision statements clearly. Also, it should determine its objectives, strategy and policy guidelines. Mission describes the purpose of the organization, it reflects its present situation whereas vision defines what the organization aims to become, it reflects its expected future state [16]. Following, this they should implement strategies and policies in action to realize their objectives. By measuring the performance of the organization, the evaluation and control stage would be completed. The aim of strategic management is to increase the performance of the organization. It helps organizations to enhance their effectiveness and efficiency. Therefore, the last step which is evaluation and control would let managers to see if the whole processes succeed or not.

\section{Ethical strategic management}

Ethics has become a hot topic in business world due to the scandals such as Enron, WorldCom which have occurred in recent 20 years. Ethical issues have become crucial for businessmen and managers in order to save their organizations and to provide them with a good reputation [17]. Providing ethical behavior is one of the aims of managers. However, there are many organizational and situational factors which affect ethical behavior in an organization [18]. Even, the managers should use ethical way of thinking while making decisions. Ethical decision making has also gained importance in business world.
To prevent unethical behavior and ethical lapses, managers should be able to use ethical decision making models. The situational and organizational factors which lead to ethical or unethical behavior are also impactful in ethical decision making [18].

As being the strategic decision makers, managers are always questioned whether their responsibilities are limited with shareholders or they have broader responsibilities. Strategic managers should consider all stakeholders while making decisions about the welfare of the organization. For organizations to exist and improve themselves, they should take stakeholders and ethical issues into consideration [17]. Thus, throughout the literature, it is mentioned that ethics and social responsibility can enhance firm's performance. Hosmer stated that ethics can be regarded as a good investment [19]. In his view, it helps organization to have good relationship with its internal and external stakeholders since it enables to build trust among these. One of the organizational aims is to increase sales, productivity and enhance the performance. Therefore, implementing ethics and social responsibility in strategies or long term plans can help organizations to enhance their performances.

Since employees are influenced by the characteristics of their own organization [18], implementation of ethics in organizational infrastructure and strategic management is crucial. Corporate ethical values are one of the dimensions of ethical behavior in business and they also lead to ethical behavior in an organization. Other factors which increase ethical behavior are the code of ethics, ethical leadership and support of whistle blowing. Code of ethics whether being principle or policy based statements influences the corporate culture and determines the procedures and guidelines for ethical behavior. There are various positions or departments such as ethics committees or chief ethics officers in organizations to provide ethical behavior and to prevent unethical acts. Also ethics trainings programs are included in most of the organization to enhance ethical behavior [17,20]. Besides these organizational factors, individual factors such as personality and moral development are also effective in creating ethical behavior $[17,18,21]$. Also, managers should make ethical decisions when they encounter with ethical dilemmas or conflicts. They may use ethical decision making based on models or ethical approaches. It is expected for managers to be ethical by using justice approach which would lead to equality and fairness in the organization among employees in terms of salary, promotion and treatment [17]. If an organization is an ethical one by providing the requirements, then the employees would be more motivated and be willing to work more efficiently and effectively. This would also enable firm to increase its performance and efficiency.

Managers consider ethics as a business issue such as costs, profits and growth. In the planning stage, they should consider all stakeholders of the organization and ethics. Ethics should be incorporated in their corporate strategy. Ethics in planning process would enhance the trust of stakeholders which would result with commitment and higher performance. This would even help the organization to gain competitive advantage. According to him, ethics should be implemented overall management of the firm [19].

Incorporating ethics and social responsibility in corporate strategies and strategic management would enable the organizations to be good citizens [19]. Even though being a good citizen may increase the costs of the organization, it may increase its performance as well. It may increase the costs since implementing ethics training programs or recruiting experts such as ethics chief officer will be recorded as expenses for the organization. However, all these steps regarding to incorporating ethics in the organization would bring a good reputation 
for the company. A good reputation increases the motivation and strengthens trust of employees which would lead to higher job satisfaction and performance. It would also attract high quality of employees. Scholars found out that people have higher tendency to work in ethical organizations. At the same time, it will take attention of the customers and society which will enable the promotion of the organization. Studies indicated that most American firms which has superior reputation based on their ethical acts, have the superior financial performance [17].

The organization' values should be congruent with the employee's values to maintain ethical behavior in that organization. Employee's aims and targets should be in accordance with the organization. If the strategy development models do not consider ethics and ambition, then it would be high likely for that organization to experience unethical behavior [22]. For example, as a strategic managements model, personal and organizational balanced scorecards can be taken into account as Rampersad did. Rampersad developed and used these models to point out the importance of ethics in strategic management model in his study [23]. He linked the critical factors to performance measures in his own model. Personal ambition and personal behavior should be balanced to lead to ethical behavior. He used Kaplan and Norton's Organizational Balanced Scorecard for his study [24,25]. Personal ambition, goals and organizational ambition, goals should be in accordance with each other. Concordance between values, mission and vision of the organization and the employee should be provided to have ethical behavior.

All the factors encouraging ethical behavior are part of strategic management. Even though most organizations mentioned that they are ethical in their mission statements and implement code of ethics, practices and managerial ethics in strategies and infrastructure of the organization, it is still questionable whether they perform ethical acts in real life. This should go beyond the statements or strategies by being realized in real life through the decisions and the moves of the organizations.

\section{Methodology}

\section{Research goal}

As a research method, interview is used. An interview is held with each respondent. Each interview is recorded and then converted into transcripts. Each interview is held in either respondent's office or home. The confidentiality of the respondents is provided and they are being informed about the confidentiality of their identities to make them feel comfortable which will enable the researchers to get impartial results. Questions regarding their perception of ethics and business life are asked to each of the respondents. Their answers which are transcribed are analyzed by the researchers.

\section{Sample and data collection}

Sample of the study consists of 8 people who are all members of Generation $Y$ and who are working. There are 4 male and 4 female who attended to the study. The entire sample has bachelor's degree.

Interview Questions:

The questions which are given below are asked to each respondent.

1. If an action could harm an innocent one, but helps you to gain positive reputation in your career, what would you do?

2. While working on a project, a team work is needed, if one of your group members does not attend to the meetings, what would you do?

3. Did you ever use a false excuse to delay turning in a report?

4. What does ethical behavior mean to you?

5. Do you think an organization should implement ethics in its long term plans or strategies?

6. Would you prefer to work in a company which has incorporated ethics in its strategic management?

7. Do you think ethics would enhance company's performance?

8. Would you take an action even though it is legal but not ethical?

\section{Analyses and results}

The female and male respondents were equally distributed and all of them have a college degree and working in a corporate company.

- Of all the respondents 5 of them said that, even if an action could harm an innocent but helps to gain positive reputation in their career, they would act professional and do the action.

- All of the respondents agree on that, if one of their group members does not attend to the meetings in a group project, they would report him/her to the managers and they would try to take him/her out of the project.

- Of all the respondents 6 of them said that, they have never delayed turning a report before, but even if they did they would have tell the truth.

- Interviewee's most common perceptions of ethics include precepts, being honest, able to make an empathy, and never to harm another for your own sake

- All of the interviewees agree on that a company should implement ethics in its long term plans because this is one of the factors that increase performance.

- All of the interviewees said that they would prefer to work in companies which have incorporated ethics in strategic management.

- Of all the respondents 7 of them said that ethics would enhance company's performance while 1 one of them said that ethics and performance are two different issues.

- Of all the respondents 6 of them said that to take an action which is legal but unethical will harm the company in its long term, while 2 of them said that in accordance with law unethical behaviors can take place for company's benefit.

As a result of our research, it can be said that Gen Y has a high tolerance on implementation of ethics in strategic management. Even though at some point they may think that for the sake of the company sometimes ethical essentials may be flexible, they resist this flexibility when their personal gain is in question. Because of this, generation feel comfortable with themselves, they prefer to tell the truth in every situation, even if they pass a deadline. Communication is an important aspect in Gen Y's life. The effects can be seen too. Their perception of ethics or an ethical behavior depends on getting use of empathy. They think very professionally on business that, even though when a friend of them doesn't work for the project, they don't feel sorry to escalate him/her from the group. And finally this group of people believes that 
ethics is something above the laws and that's why they do not prefer to take an action which is legal but unethical.

\section{Conclusion}

As also mentioned in the literature, especially, in business life individuals whom are part of Gen Y give more importance to ethics than other members of any generation. Ethics is crucial for them and they conform to ethical codes, guidelines or principles. Whenever they encounter with an ethical conflict, they seem to make a decision based on ethicality of that act. It can be assumed that they are followers of deontology as an ethical approach. They do not hesitate to get use of whistle-blowing whenever they find out misconduct or unethical behavior. People who do not comply with ethical principles could easily be left out by this generation even if they are friends or someone from their in-group.

The research of the study also indicated results which are in accordance with the literature. Based on the literature, it is expected for Gen $\mathrm{Y}$ to perform ethical behavior and take ethical principles into consideration in business life through their actions. The study deployed a qualitative research method which in depth interviews was held with the participants of Gen Y. All of the participants were holding a bachelor's degree and were employed. Depending on the answers given by participants, the findings indicated that whenever they encounter with misconduct or an unethical act, they try to solve the issues following ethical guidelines or principles. They may easily end up their business or professional relationship with a friend when they realize that their friend is behaving unethically. The answers of participants show that ethics is a priority for them in their business life. They claim that they prefer being ethical over gaining success, good reputation or gaining more profits. Majority of the participants mentioned that it is more important for them to be ethical in business life and they may give up good reputation or chances or promotion in order to perform ethical behavior. They also stated that they prefer to work in organizations which incorporated ethics into their infrastructure and strategic management. High percentage of the participants included that the organization must reflect its ethical behavior with its act rather than just stating in its mission statement or principles. According to participants, long term business plans and strategies of the organizations should also be shaped in accordance with ethical principles. They highlighted the importance of implementing ethics into strategic management of an organization. They believe that incorporating ethics into strategic management would enable the organization to increase its performance. Thus, it can be stated that the results were as expected.

Since Gen Y are now in the business life and expected to be the future managers and leaders in business world, it is important for them to have an ethical point of view especially in terms of professional life. Ethics has gained critical importance due to ethical lapses and scandals which have occurred lately. Therefore, ethical managers and leaders are demanded in business world. Many training programs have been developed in order to enhance ethics in organizations. Managers are forced to attend to these ethics training programs to prevent unethical behavior in organizations. The organizations should incorporate ethics in its strategic management by adapting its infrastructure accordingly and implementing codes of ethics, supporting whistle-blowing and ethical leadership. Besides implementing ethics in their mission statements, business plans and strategies, they should demonstrate it with their acts and actions. Since Gen Y gives priority to ethics and ethical behavior, it would be high likely for them to incorporate ethics into strategic management which would indeed increase the organization's performance as well. As Gen Y being the future managers, it would be much easier for organizations to implement ethics into strategic management within employment of Gen Y in their organizations.

The study contributes to literature since it highlights on Gen Y and their ethical view on incorporating ethics into strategic management. Most of the studies regarding ethical strategic management does not consider category of generation, therefore, the study fills a gap in the literature by taking generation differences into consideration in ethical strategic management. Also, most of the empirical researches on this subject are studied in Western countries. Since this study takes place in non-western country, it brings a different perspective. The study could also be considered for managerial implications. The business men may consider recruiting members of Gen $\mathrm{Y}$ since their priority is ethics in professional life, it would enable them to enhance ethics and incorporate ethics into strategic management.

\section{References}

1. Tolbize A (2008) Generational differences in the workplace. Research and Training Center on Community Living. University of Minnesota, Minneapolis.

2. Page D, Wong TP (2000) A conceptual framework for measuring servant leadership. In S Abjibolosoo (Ed), The human factor in shaping the course of history and development. University Press of America, Lanham.

3. Ehrhart MG (2004) Leadership and procedural justice climate as antecedents of unit-level organizational citizenship behavior. Personnel Psychology 57: 6194.

4. Strutton D, Pelton LE, Ferrell OC (1997) Ethical behavior in retail settings: Is there a generation gap? Journal of Business Ethics 16: 87-105.

5. Howe N, Strauss W (2000) Millenials rising: The next great generation. Random House, New York.

6. Twenge JM, Foster JD (2008) Mapping the scale of the narcissism epidemic: Increases in narcissism 2002-2007 within ethnic groups. Journal of Research in Personality 42: 1619-1622.

7. Bracker J (1980) The Historical Development of the Strategic Management Concept. The Academy of Management Review 5: 219-224.

8. Ansoff HI (1965) Corporate Strategy. Mc Graw-Hill, New York.

9. Neumann JV, Morgenstern O (1947) Theory of games and economic behavior Princeton University Press.

10. Drucker $P$ (1954) The Practice of Management. Academy of Management Harper \& Brothers, New York 17: 16-23.

11. Schendel D, Hofer C (1979) Introduction. D Schendel and C Hofer (eds) Strategic Management: A New View of Business Policy and Planning (Little Brown, Boston, MA) pp: 1-12.

12. Mintzberg H (1979) The Structuring of Organizations. Prentice- Hall, US pp: 322-353

13. Thompson JD (1967) Organizations in Action: Social Science Bases of Administrative Theory. Transaction Publishers, New Jersy.

14. Lawrence PR, Dyer D (1983) Renewing Americon industry. Human Resource Management 22: 475-478.

15. Faulkner DO, Campbell A (2003) The Oxford Handbook of Strategy: A Strategy Overview and Competitive Strategy. Oxford, UK

16. Wheelen TL, Hunger DJ (2012) Strategic Management and Business Policy: Toward Global Sustainability. Pearson Learning Solutions, lowa State University, USA.

17. Daft RL (2010) Management. South-Western Cengage Learning, USA.

18. Hunt SD, Vitell S (1986) A General Theory of Marketing Ethics. Journal of Macromarketing 6: 5-16.

19. Hosmer LT (1994) Strategic planning as if ethics mattered. Strategic Management Journal 15: 17-34. 
Citation: Celikdemir DZ, Paker IT (2016) Incorporating Ethics into Strategic Management with Regards to Generation Y's View of Ethics. J Bus Fin Aff 5: 175. doi:10.4172/2167-0234.1000175

Page 6 of 6

20. Miller DS, Catt SE, Carlson JR (1996) Fundamentals of Management: a framework for excellence. West Publishing Company, Minneapolis.

21. Ferrell OC, Fraedrich J, Ferrell L (2010) Business Ethics: Ethical Decision Making \& Cases. South-Western Cengage Learning, USA.

22. Rampersad HK (2003) The links between individual learning, collective learning and ethics. Training and Management Development Methods 17: 1.

23. Rampersad HK (2003) Total Performance Scorecard: Redefining management to achieve performance with integrity. Butterworth-Heinemann Business Books, Elsevier Science, Massachusetts.

24. Kaplan RS, Norton DP (1996) The Balanced Scorecard: translating strategy into action. Harvard Business School Press, Boston.

25. Kaplan RS, Norton DP (2000) The Strategy focused Organization: how balanced scorecard companies thrive in the new business environment. Harvard Business School Press, Boston. 